Original Research Article

\title{
Evaluation of the protective effect of Paeonia emodi Wall on rat model of Parkinson's disease induced by 6 hydroxy dopamine
}

\author{
Sharmila V. Jalgaonkar ${ }^{1}$, Abhay P. Kamble ${ }^{1}$, Urwashi I. Parmar ${ }^{1 *}$, Dnyaneshwar G. Kurle ${ }^{1}$, \\ Moin S. Bedrekar ${ }^{1}$, Malvika Gursahani ${ }^{2}$
}

${ }^{1}$ Department of Pharmacology and Therapeutics, Seth G. S. Medical College and K. E. M. Hospital, Parel, Mumbai 400012, Maharashtra, India ${ }^{2}$ Student, Institute of Chemical Technology, Matunga, Mumbai 400019, Maharashtra, India

Received: 21 June 2018

Revised: 22 September 2018

Accepted: 26 September 2018

*Correspondence to:

Dr. Urwashi I. Parmar,

Email: drurwashi@gmail.com

Copyright: (C) the author(s), publisher and licensee Medip Academy. This is an openaccess article distributed under the terms of the Creative Commons Attribution NonCommercial License, which permits unrestricted noncommercial use, distribution, and reproduction in any medium, provided the original work is properly cited.

\begin{abstract}
Background: Generation of reactive oxygen species together with paucity of antioxidant defense is considered as an important cause for dopaminergic neuronal death. Review of literature indicates that none of the drugs so far studied for preventing the PD were found to be promising for use. Therefore, the present study was planned to evaluate the neuroprotective effect of Paeonia emodi Wall (PEW) in 6-hydroxy dopamine induced Parkinson's disease (PD) model.

Methods: The study was conducted on Wistar rats where Parkinson's disease was induced by producing the striatal 6-hydroxy dopamine lesions. The test animals received ethanolic extract of PEW at dose of 200 and $300 \mathrm{mg} / \mathrm{kg}$ for 28 days. Circling behavior, spontaneous locomotor activity, muscular coordination and akinesia were studied. Antioxidant levels were assessed by biochemical estimation and histopathology was carried out for dopaminergic neuronal loss. Results: PEW ethanolic extract showed significant dose dependent recovery in number of circlings, line crossing, muscular coordination and akinesia. A significant increase in MDA levels and decreased GSH level in PEW treated groups was observed in test groups as compared to control group $(\mathrm{p}<0.05)$. Normal architecture was retained only in PEW 300mg/Kg $(\mathrm{p}<0.05)$. L-Dopa did not showed effect on biochemical and histological parameters.

Conclusions: The ethanolic extract of PEW showed neuroprotective activity against 6-hydroxy dopamine induced Parkinson's disease in rats in both 200 and $300 \mathrm{mg} / \mathrm{kg}$ doses. The protective action of PEW in PD can be because of its ability to reduce the oxidative stress.
\end{abstract}

Keywords: Biochemical, Histopathological, Oxidative stress, Paeonia Emodi Wall, Stepping test, Stereotaxic, 6-Hydroxydopamine

\section{INTRODUCTION}

Parkinson's disease (PD) is the $2^{\text {nd }}$ most common form of progressive neurodegenerative disorder characterized by loss of $\sim 50-70 \%$ of dopaminergic neurons in substantia nigra pars compacta and the presence of intra-neuronal inclusions termed as Lewy bodies. ${ }^{1}$ Studies suggest that massive oxidative stress, free radical formation, genetic susceptibility, and programmed cell death, have a role in the development of PD. ${ }^{2}$
The prevalence of the PD is found in the range from 100 to 200 and the annual incidence is found to be 15 per 100,000 people. ${ }^{3}$ PD constitutes $5-60 \%$ of total movement disorders with variations in geographical areas all over the world. ${ }^{4}$

Currently, main drugs used for the treatment for PD include levodopa (L-dopa), bromocriptine, amantadine and selegiline. ${ }^{1}$ These drugs provide symptomatic relief during early PD but do not effectively tackle tremor, 
postural instability and cognitive deficits and many patients develop motor complications with long-term treatment.

Bioactive derivatives of plants such as flavonoids, stilbenoids and alkaloids possess potent anti-oxidative properties. These naturally occurring phytochemicals can also promote mitochondrial function and serve as important cognitive enhancers. ${ }^{5}$ One such plant is Paeonia emodi Wall (PEW).

PEW is a well-known Himalayan medicinal plant from the genus Paeonia in the family Paeoniaceae. This plant is used widely in Unani and Ayurvedic systems of medicine and is commonly known as Ud-salib and Chandra/ Joshimath respectively. It is used in various disease conditions like uterine diseases, biliousness, dropsy and nervous affections. ${ }^{6}$ In Ayurveda, PEW is considered as a nervine tonic and has a mention for its use in Kampavata which has similar symptoms and pathology resembling PD in modern medicine. ${ }^{7,8}$

Although various parts of PEW are used in therapy, roots of these plants have been used to cure different diseases since centuries. ${ }^{7}$ Phytochemical studies have demonstrated the presence of various bioactive compounds like phenolics, oligostilbenes and flavonoids in the roots of PEW. ${ }^{9}$ Flavonoids in PEW react with the reactive radical resulting in more stable, less reactive radical, thus exerting antioxidant properties to it. $^{7}$

Many of the local and traditional claims for the use of different parts of PEW have been scientifically established by in vivo and in vitro methods. ${ }^{6}$ However, the use of PEW in the experimental animal models of PD is still not established. 6-OHDA induced PD animal model specifically produces reactive oxygen species-induced slow, progressive and selective destruction of the dopaminergic cells which is considered as an important pathological feature of PD. It is commonly used as a unilateral model because bilateral injection of this compound into striatum produces severe adipsia, aphasia and also death. ${ }^{10}$

Objectives of our study were to evaluate the effect of ethanolic extract of PEW on behavioural tests in 6-OHDA induced PD in wistar rats in vivo and to evaluate antioxidant and free radical scavenging property of PEW in vitro.

\section{METHODS}

Institutional Animal Ethics Committee (60/PO/ReBi/S/99/CPCSEA) permission was taken before commencement of the study. 30 wistar rats, of either sex, each weighing between 200-300grams in the Centre for Animal Studies of our institute were used. Rats were housed in temperature-controlled room: $25 \pm 2^{\circ} \mathrm{C}$ with a 12 hour light/dark cycle and $57 \pm 7 \%$ relative humidity under standard hygienic conditions and had free access to fresh tap water and pelleted diet.

\section{Chemicals and study drugs}

Ketamine, 6-OHDA, Desipramine, Apomorphine hydrochloride and L-dopa were procured from SigmaAldrich Co., USA. All other chemicals were of the analytical grade.

Roots of PEW were procured from Medzus Healthcare Pvt. Ltd., Goregaon Mumbai. These were collected from North-Indian states of Himalaya during the month of January 2016. Roots were washed properly, dried at $45^{\circ} \mathrm{C}$ for 48 hours and were then subjected for grinding to make dry powder. The powder was stored in a sterile container for $4^{\circ} \mathrm{C}$ until extraction and was subjected to extraction for obtaining ethanolic extract one day before the experiment. The extraction was carried out by soxhlet apparatus (70$80^{\circ}$ ) under 8 parts of $90 \%$ ethanol with boiling for 5 hours. Extract was filtered, and spray dried to get brown powder. The percentage w/w extract of the powder was $56.46 \%$. The extract was administered to animals by suspending in $0.5 \%$ carboxy methyl cellulose.

\section{Stereotaxic procedure for a unilateral partial lesion in the right striatum by neurotoxin 6-OHDA ${ }^{11}$}

The animal was weighed and was administered anesthetic, ketamine $(150 \mathrm{mg} / \mathrm{kg} / \mathrm{b} . w$.$) along with xylazine$ (10mg/kg/b.w.). Rats were placed on the stereotaxic apparatus (Inco Ambala) platform. The ear bars were adjusted, and rats were fixed with the nose bar. An anterior-posterior incision of about $2.5 \mathrm{~cm}$ was made on the midline of the scalp until the back of the ears. After identifying bregma the needle was inserted through a rightsided burr hole into the striatum with the following coordinates, Antero-posterior (AP): $0.5 \mathrm{~mm}$; Lateral $2.5 \mathrm{~mm}$; and Dorso-ventral (DV) $5 \mathrm{~mm}$ from bregma with a tooth bar set at $0 \mathrm{~mm}$ from dura. ${ }^{12}$

\section{Postoperative care}

Recovery from anaesthesia took approximately 4-5 hours. Rats were kept in a well-ventilated room at temperature of $25 \pm 3^{\circ} \mathrm{C}$ in individual cages until they gained full consciousness. They were housed together in separate rooms with 1 animal per cage. Food and water were mixed with $1 \mathrm{ml}$ of Ibuprofen kept inside the cages for two days, allowing easy access to animals. After 3-4 days, animals were given normal food and water. Bedding of the cages were changed twice per week.

\section{Experimental design}

Table 1 gives details of the experimental protocol followed. Rats were divided into five groups of 6 in each. All animals were treated with drugs orally by gavage for once daily for 30 days after stereotactic injection. The final volume administered to each rat was $1 \mathrm{ml}$ (Table 1). 
Table 1: Experimental protocol $(n=30)$.

\begin{tabular}{|c|c|c|}
\hline Group & $\begin{array}{l}\text { Description of } \\
\text { group }\end{array}$ & Drug/dose \\
\hline $\begin{array}{l}\text { Group 1: Sham } \\
\text { operated (SHO) }\end{array}$ & $\begin{array}{l}4 \mu 10.9 \% \text { saline with } \\
0.01 \% \text { ascorbic acid } \\
\text { via stereotactic } \\
\text { injection in striatum }\end{array}$ & $\begin{array}{l}\text { Normal } \\
\text { saline }\end{array}$ \\
\hline $\begin{array}{l}\text { Group 2: Disease } \\
\text { Control (DC) }\end{array}$ & \multirow{4}{*}{$\begin{array}{l}10 \mu \mathrm{g} \text { OHDA in } \\
2 \mu \mathrm{g} / \mu \mathrm{l}, \text { in } 0.9 \% \\
\text { saline with } 0.01 \% \\
\text { ascorbic acid via } \\
\text { stereotactic injection } \\
\text { in striatum }\end{array}$} & $\begin{array}{l}\text { Normal } \\
\text { saline }\end{array}$ \\
\hline $\begin{array}{l}\text { Group 3: Positive } \\
\text { control (PC) }\end{array}$ & & $\begin{array}{l}6 \mathrm{mg} / \mathrm{kg} \mathrm{L}- \\
\text { dopa }\end{array}$ \\
\hline $\begin{array}{l}\text { Group 4: Study } \\
\text { drug low dose: } \\
\text { ethanolic extract } \\
\text { of PEW (SDLD) }\end{array}$ & & $200 \mathrm{mg} / \mathrm{kg}$ \\
\hline $\begin{array}{l}\text { Group 5: Study } \\
\text { drug high dose: } \\
\text { ethanolic extract } \\
\text { of PEW (SDHD) }\end{array}$ & & $300 \mathrm{mg} / \mathrm{kg}$ \\
\hline
\end{tabular}

\section{Evaluation methods}

\section{Neuro-behavioral assessment $t^{13}$}

All behavioral tests were performed on $1^{\text {st }}, 2^{\text {nd }}, 3^{\text {rd }}$ and $4^{\text {th }}$ week after the stereotactic injection of 6 OHDA in the striatum of rats.

\section{Apomorphine-induced circling behavior ${ }^{14,15}$}

To assess extent of neuronal loss. Rats were injected with apomorphine hydrochloride $0.5 \mathrm{mg} / \mathrm{kg}$ IP. After 15 minutes, number of contralateral turns were recorded for a 30-minute period.

\section{Open field test: Measurement of locomotor activity}

The apparatus used to measure locomotor activity was a wooden square box, $40 \mathrm{~cm}$ x $40 \mathrm{~cm}$ with $30.5 \mathrm{~cm}$ high walls. Its floor is divided into nine smaller squares of equal dimensions $(13.3 \mathrm{~cm}$ x $13.3 \mathrm{~cm})$. For open field observations, each rat was individually placed in the centre of the arena, and variables were recorded for 30 minutes. Between trials, the box was cleaned with $10 \%$ alcohol and paper tissue to eliminate the odour of the previous rats. Variables: Horizontal locomotor activity i.e. grid lines crossed and vertical locomotor activity i.e. rearing.

\section{Rota rod test: measurement of motor coordination}

Rats underwent pre-test on the rota rod apparatus 1-day prior. Animals demonstrating ability to remain on revolving rod for at least 1 minute were used. Animals were acclimatized to the apparatus for 30 minutes before test. Speed of rota rod was set at 10 cycles per min. Variables- Latency to fall and a number of falls within the test period of 5 minutes.

\section{Stepping test: For the measurement of akinesia}

The rat was held with one hand by the experimenter fixing the hind limbs (raising the torso) and with other hand fixing the forelimb that is not to be monitored. In this way, the other forepaw had to bear the weight. When the rats moved with a speed of $90 \mathrm{~cm}$ per $5 \mathrm{~s}$ in forward and backward direction along the table, the free forelimb had to step with the movement of the experimenter to keep balance. The steps taken to keep balance were recorded as the adjusting steps. Variables- Number of the adjusting steps for the contralateral forepaw for both forward and backward direction, calculated for period of 10 seconds.

After the completion of the behaviour test, animals were anesthetized with a lethal dose of sodium pentobarbital $(50 \mathrm{mg} / \mathrm{kg})$. The brain from rats removed after cervical decapitation were utilised for histopathological studies and biochemical estimation as explained below.

\section{Histopathology}

To test the extent of lesion in the striatum. ${ }^{16}$ Right-sided cerebral hemisphere was cut into longitudinal sections. After identification of striatum, it was fixed with $10 \%$ formalin for 24 hours and embedded in paraffin wax. Fixed tissue of striatum $5 \mu \mathrm{m}$ thickness were stained with hematoxylin and eosin dye and observed for neuronal degeneration (necrosis, cellular infiltration and haemorrhage) under an ordinary microscope. The area of neuronal degeneration was evaluated in 10 microscopic fields. Histopathology images were read under $10 \mathrm{X}$ magnification. Quantitative assessment of striatal cell damage was carried out by comparing the number of damaged cells concerning the total number of cells in the explored fields of each experimental condition and expressed as a percentage per field (total 10 fields). More than $60 \%$ neuronal destruction after 28 days was considered significant.

\section{Histopathology grading}

As no universally accepted grading of histopathology for brain striatum is available, authors have used grading system described as follows: 0 NAD (no abnormality detected) - $<10 \%, 1+$ Minimal - $10-20 \%, 2+$ mild $-20-$ $40 \%, 3+$ moderate $-40-60 \%, 4+$ marked $-60-80 \%, 5+$ Severe - $>80 \%$

\section{Biochemical studies}

The remaining tissue of right-side brain (excluding striatum) was used for biochemical analysis. The tissue kept in cooled $0.9 \%$ saline in a small container was weighed and homogenized in cold phosphate buffer $(0.05$ $\mathrm{M}, \mathrm{pH}$ 7.4). Homogenates were centrifuged at 10000 rotations per minute (rpm) for $10 \mathrm{~min}$ at $4^{\circ} \mathrm{C}$. Supernatant obtained was centrifuged at $15000 \mathrm{rpm}$ for 1 hour at $4^{\circ} \mathrm{C}$ and used for further estimation of glutathione (GSH) and malondialdehyde (MDA). 


\section{Statistical analysis}

The statistical analysis was performed using Graph-Pad Instat software version 3.06. The results were expressed as mean \pm SD. The level of significance ( $p$-value) for each comparison in the analysis was calculated at 0.05. The normality of the data was assessed using the Kolmogorov - Smirnov test. The parametric data between five groups was compared using one-way-ANOVA test followed by post hoc Tukey's test while non-parametric data between five groups was analyzed using Kruskal-Wallis test followed by post hoc Dunn's test.

\section{RESULTS}

\section{Neuro-behavioral assessment}

Significant increases in the number of apomorphineinduced rotations were observed in the 6- OHDA-lesioned rats compared to the control group. Rats receiving PEW (200 and 300mg/kg) exhibited significant dose dependant attenuation in circling behaviour, indicating that PEW prevented neuronal loss induced by6- OHDA. PEW also showed dose dependent recovery in the open field test parameters i.e. line crossed and rearing. Similarly, muscular coordination as evaluated by rota rod test was significantly reduced in OHDA lesioned rats. Both L-dopa and PEW (200 and $300 \mathrm{mg} / \mathrm{kg}$ ) showed recovery in, time for fall and number of falls. There was a significant impairment in contralateral, left-paw adjusting steps in both forward and backward direction. (data shown only for forward direction) in 6-OHDA lesioned rats. PEW showed recovery in this parameter but only in low dose $200 \mathrm{mg} / \mathrm{kg}$. In all the above behavioural tests, positive control L-Dopa showed significant improvement compared to lesioned rats. Only improvement seen with $\mathrm{PEW} 300 \mathrm{mg} / \mathrm{kg}$ was comparable to L Dopa (Table 2).

Table 2: Effect of ethanolic extract of PEW on neuro-behavioural parameters in 6-OHDA induced PD in rats.

\begin{tabular}{|c|c|c|c|c|c|c|}
\hline \multirow[b]{2}{*}{ Groups } & \multirow{2}{*}{$\begin{array}{l}\text { Apomorphine } \\
\text { induced circling } \\
\text { (no. of } \\
\text { contralateral } \\
\text { turns) }\end{array}$} & \multicolumn{2}{|l|}{ Open Field Test } & \multicolumn{2}{|l|}{ Rota rod test } & \multirow{2}{*}{$\begin{array}{l}\text { No. of } \\
\text { contralateral } \\
\text { forepaw } \\
\text { adjusting } \\
\text { steps }\end{array}$} \\
\hline & & $\begin{array}{l}\text { No. of lines } \\
\text { crossed }\end{array}$ & $\begin{array}{l}\text { No. of } \\
\text { rearing } \\
\text { episodes }\end{array}$ & $\begin{array}{l}\text { Latency to } \\
\text { fall in } \\
\text { seconds }\end{array}$ & No. of falls & \\
\hline Sham Operated & $18.33 \pm 4.63$ & $165.33 \pm 18.95$ & $20.33 \pm 2.25$ & $32.16 \pm 4.91$ & $13.16 \pm 1.83$ & $7.17 \pm 0.75$ \\
\hline Disease Control & $121.7 \pm 6.77^{\#}$ & $82.83 \pm 11.99^{\#}$ & $6.33 \pm 1.03^{\#}$ & $12.16 \pm 2.31 \#$ & $32.16 \pm 5.94^{\#}$ & $2.50 \pm 0.54^{\#}$ \\
\hline L Dopa & $58.67 \pm 7.5^{*}$ & $136.83 \pm 12.7^{*}$ & $17.83 \pm 2.9^{*}$ & $31.83 \pm 3.9 *$ & $12.5 \pm 2.07^{*}$ & $4.83 \pm 1.16^{*}$ \\
\hline PEW 200mg/kg & $80.5 \pm 7.5^{* \$}$ & $109.33 \pm 15.7^{* \$}$ & $13.33 \pm 2.5^{* \$}$ & $22.5 \pm 4.5^{* \$}$ & $19.83 \pm 3.25^{*} \$$ & $3 \pm 0.89^{\$}$ \\
\hline $\mathrm{PEW} 300 \mathrm{mg} / \mathrm{kg}$ & $60.8 \pm 8.5^{* \mathrm{~ns}}$ & $133.33 \pm 14.9^{* \mathrm{n}_{\mathrm{n}}}$ & $17.5 \pm 2.4^{* \mathrm{~ns}}$ & $30 \pm 5 * \mathrm{~ns}$ & $13.5 \pm 3.39^{*} \mathrm{~ns}$ & $4.67 \pm 1.21^{* \mathrm{~ns}}$ \\
\hline
\end{tabular}

All values expressed as mean \pm SD, $n=6$. ${ }^{*} \mathrm{p}<0.05$ vs disease control, \#p<0.05 vs sham-operated group, $\$ p<0.05$ vs positive control, ns not significant, One way ANOVA followed by post hoc Tukey's test

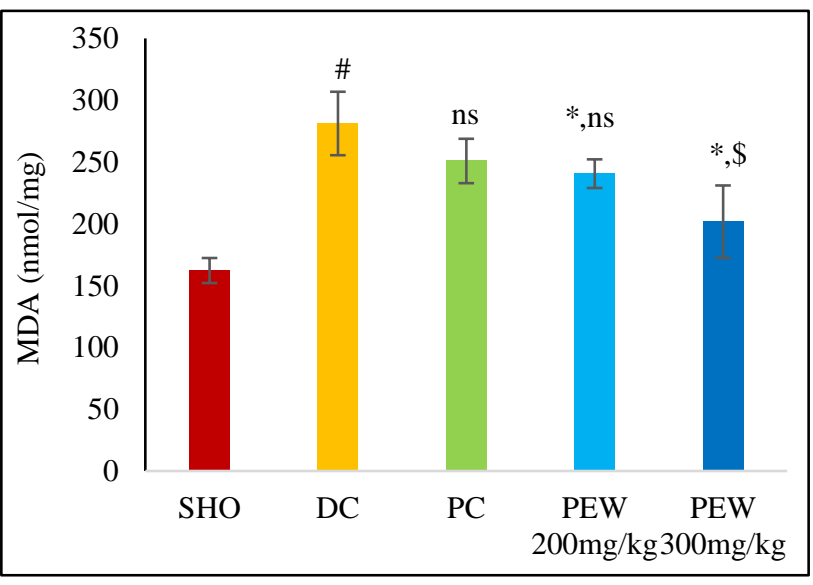

All values expressed as mean $\pm \mathrm{SD}, \mathrm{n}=6$. $* \mathrm{p}<0.05$ vs disease control, \#p<0.05 vs sham-operated group, $\$ \mathrm{p}<0.05$ vs positive control, ns- not significant. One way ANOVA followed by post hoc Tukey's test.

Figure 1: Effect of ethanolic extract of PEW on MDA at the end of 4 weeks in 6-OHDA induced PD rats.

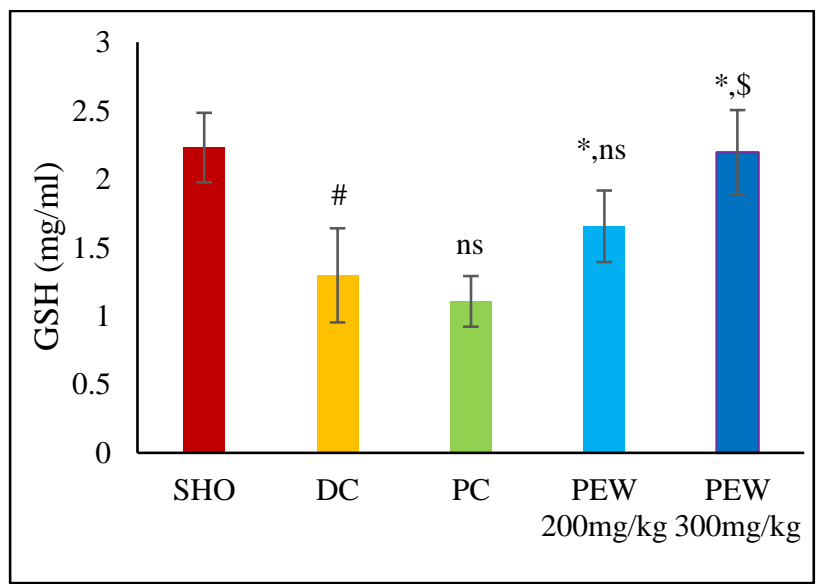

All values expressed as mean $\pm \mathrm{SD}, \mathrm{n}=6 .{ }^{*} \mathrm{p}<0.05$ vs disease control, \#p<0.05 vs sham-operated group, $\$ \mathrm{p}<0.05$ vs positive control, ns- not significant. One way ANOVA followed by post hoc Tukey's test.

Figure 2: Effect of ethanolic extract of PEW on GSH levels at the end of 4 weeks in 6-OHDA induced PD rats. 


\section{Biochemical analysis}

The 6 OHDA lesioned rats showed significant increase in MDA levels and decreased GSH level compared to sham control. There was significant reduction in brain MDA levels in a dose-dependent manner with both PEW 200 and $300 \mathrm{mg} / \mathrm{kg}$. However, GSH were increased only with PEW (Figure 1 and Figure 2).

Table 3: Effect of ethanolic extract of PEW on the striatal dopaminergic neurons at the end of 4 weeks in 6-OHDA induced PD rats.

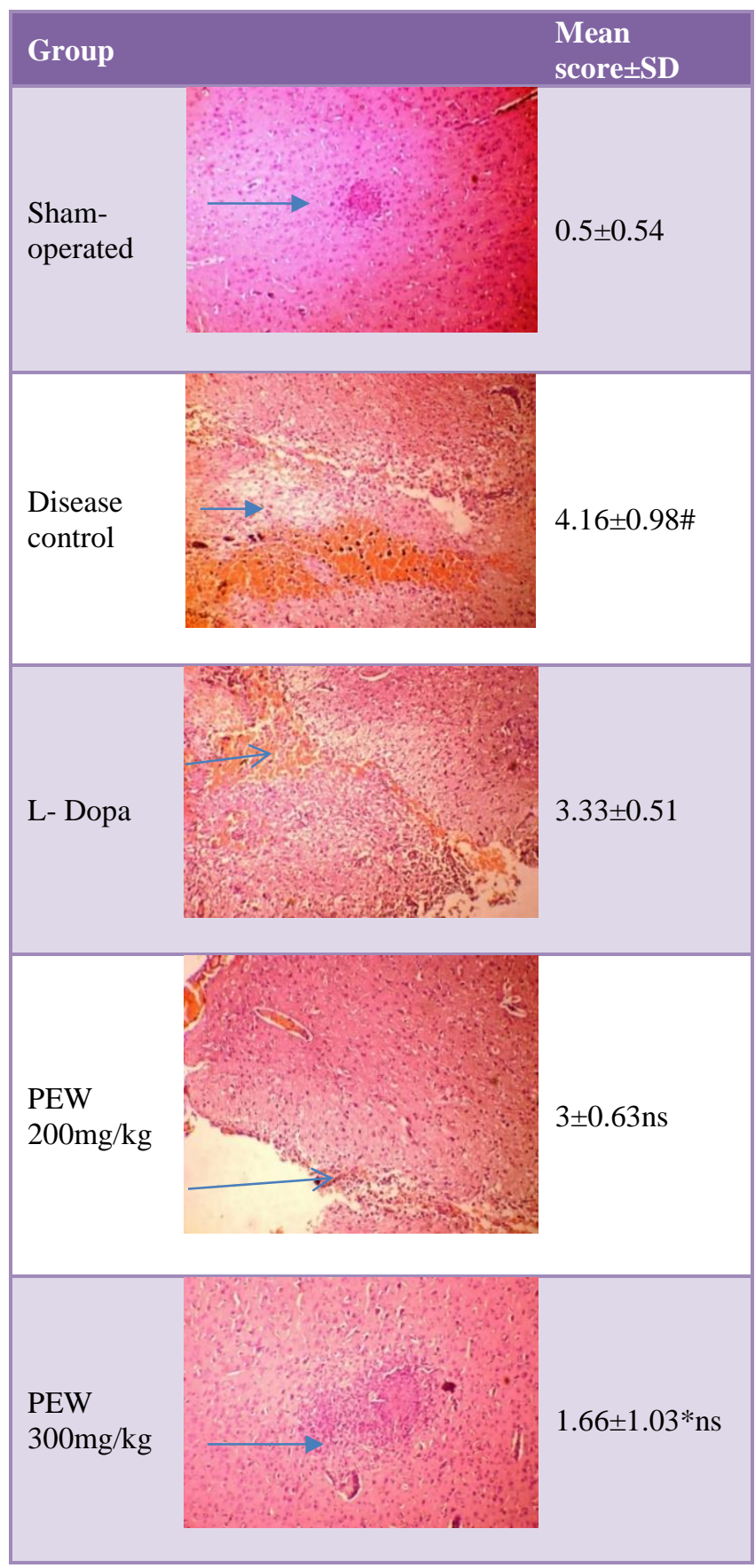

$\mathrm{n}=6$, values expressed as mean \pm SD. $*-\mathrm{p}<0.05$ vs disease control, $\$-\mathrm{P}<0.05$ compared to positive control, \#p<0.05 vs shamoperated group, ns - not Significant Kruskal Wallis Test followed by post hoc Dunn's test.

\section{Histopathology}

There was a significant neuronal loss in 6 OHDA lesioned rats group compared to sham control group which showed normal architecture of neuronal cells. Amongst the rats with two doses of study drugs, normal architecture was retained in only PEW 300mg/Kg ( $\mathrm{p}<0.05)$. L Dopa did not showed effect on biochemical as well as histological parameters (Table 3).

Arrow indicates cell infiltration, haemorrhage and cytoplasmic vacuolation changes in brain parenchyma corresponding to neuronal loss. The tissues were stained with HandE and photographs were taken on 10X magnification.

\section{DISCUSSION}

In PD the current drugs improve the motor symptoms and quality of life of patients with PD in the early stages of the disease but after few years of therapy patients become progressively more disabled.${ }^{17}$ Hence, there is need of safe and efficacious alternative for management which can retard the disease progression and improve the quality of life of patients suffering from PD even during a later stage of the disease.

PD is called as Kampavata in Ayurveda, meaning 'exaggerated shaking movements of the limbs.' Various medicinal plants used in Ayurveda including mucuna pruriens, a natural source of L-dopa have been subjected to experimental studies for their use in PD. ${ }^{18}$

One of the medicinal plant mentioned in Ayurveda for the treatment of PD is Paeonia emodi Wall. ${ }^{6}$ A phytochemical screening conducted by Uddin et al, showed that both aqueous and ethanolic extract of PEW have excellent antioxidant and radical scavenging properties of phytochemicals including flavonoids in PEW with potent antioxidant activity. ${ }^{19}$ Apart from this in-vitro study, invivo studies conducted by Zaidi et al, in pentylenetetrazol (PTZ) induced epilepsy and Zargar et al, in high fat dietinduced oxidative stress model have demonstrated antioxidant activity of PEW., ${ }^{9,20}$

The doses of the PEW, 200mg/kg/b.w. (low dose, LD) and $300 \mathrm{mg} / \mathrm{kg} / \mathrm{b}$.w. (high dose, HD) were selected from the Ayurvedic literature and previous studies to evaluate if there is dose-dependent effect of PEW in an animal model of PD. ${ }^{20,21}$ The positive control used for the study was Ldopa.

The two most widely used toxin-induced animal models of PD are the classical 6-OHDA-treated rat and the MPTPtreated mouse. 6-OHDA is taken up by the dopaminergic neurons, readily oxidizes to form reactive oxygen species such as hydrogen peroxide which reduce striatal levels of antioxidant enzymes like reduced glutathione (GSH). This model also shows hallmark clinical symptoms (akinesia, rigidity), biochemical features (reduced striatal dopamine) 
and pathological features (nigro-striatal tract degeneration) of PD thus indicating high face validity. This model has been extensively used for the evaluation of novel neuroprotective agents. ${ }^{22}$ 6-OHDA when infused either unilaterally or bilaterally in selective brain areas like basal ganglia, substantia nigra pars comapcta, median forebrain bundle and striatum will result in different physiological and behavioural deficits. A study conducted by Zhang et al, have proven that unilateral injection of 6OHDA in rat striatum has more than $90 \%$ success rate for development of PD model. ${ }^{23}$

The results of this study clearly showed the protective effect of PEW on a rat model of PD induced by 6-OHDA. The neuronal loss was approximately $60-80 \% .^{24,25}$ Various previous studies have confirmed that administering 6OHDA into the striatum, produces neuronal loss which is minimal at week 1 , reaching a maximum within 2-3 weeks. ${ }^{26}$ The study findings of phase 1 are also in line with these studies. This study reported an appreciable decrease in a number of circling and restoration of behavioural deficits compared to 6-OHDA lesioned rats at week 4 with both SDLD and SDHD. It has been well established that the ability of a drug to reduce contralateral rotational behaviour induced by 6-OHDA, directly correlates with its ability to revert PD motor impairment. ${ }^{14,27}$ After 6-OHDA lesion in rats, forepaw adjusting step deficits is suggested as a model for akinesia of PD. Animals with a partial intra striatal lesion $(50-70 \%)$ display deficits in the adjusted stepping test, which are maximal around two weeks postlesion. ${ }^{28,29}$ In this study we found a reduction in akinesia in rats treated with ethanolic extract of low as well as a high dose of PEW.

Malondialdehyde (MDA), an end product of the lipid peroxidation, is increased and GSH, which protects mitochondrial activities and reduce oxidative stress in neurons is decreased in PD. In this study ethanolic extract of PEW significantly reversed these effects of 6-OHDA, revealing the antioxidant activity of the extract. This antioxidant effect of ethanolic extract of PEW is also supported by previous studies in vitro as well in vivo studies. ${ }^{9,19}$

It is reported that on intra-striatal administration of 6hydroxydopamine, the dopaminergic neurons are specifically degenerated by increased oxidative stress and apoptosis. PEW in higher dose showed protective effect on striatal neurons with clear texture of striatal tissue.

In this study L-dopa improved motor symptoms in 6 OHDA lesioned rats however it failed to prevent degeneration or protect the neurons against oxidative damage. The similar results were seen by Khadira et al, who have used L-dopa as positive control in their study. ${ }^{30}$

The present study is the first study to examine the effect of ethanolic extract of PEW in 6-OHDA induced PD in rats. Salient feature of this study was evaluation of the drug in
PD model using combinations of behavioural, biochemical and histopathological variables.

\section{CONCLUSION}

Based on neurobehavioral tests, biochemical and histopathological analysis, we have demonstrated the neuroprotective potential of ethanolic extract of PEW in 6 OHDA lesioned rats dose dependently i.e. both high and low doses. It might exert its anti-parkinsonian effect by its ability to reduce the oxidative stress. This suggests that it has therapeutic potential to prevent PD. The higher dose of ethanolic extract of PEW is having better antiparkinsonian potential compared to the lower dose. However, further investigations like immunohistochemistry and assay to find striatal dopamine level, are needed to strengthen our findings of PEW extract responsible for the anti-parkinsonian effect.

Funding: Funding sources from Diamond Jubilee Society Trust (DJST) and Research Society of Seth GS Medical College and KEM Hospital, Parel, Mumbai, Maharashtra, India

Conflict of interest: None declared

Ethical approval: The study was approved by the Institutional Animal Ethics Committee (60/PO/ReBi/S/99/CPCSEA)

\section{REFERENCES}

1. Olanow CW SA. Parkinson's Disease and Other Movement Disorders. In: Longo DL, Fauci AS, Kasper DL, Hauser SL, Jameson JL, Loscalzo J (eds.). In: Harrison's principles of internal medicine. $18^{\text {th }} \mathrm{Ed}$. USA: Mc Graw Hill; 2012:3327.

2. Crotty GF, Ascherio A, Schwarzschild MA. Targeting urate to reduce oxidative stress in Parkinson disease. Exp Neurol. Elsevier Inc. 2017;298:210-24.

3. Tysnes OB, Storstein A. Epidemiology of Parkinson's disease. J Neural Transm. Springer Vienna. 2017;124(8):901-5.

4. Muthane UB, Ragothaman M, Gururaj G. Epidemiology of Parkinson's Disease and Movement Disorders in India. Problems and Possibilities. October. 2007;55(October):14-6.

5. Essa MM, Vijayan RK, Castellano-Gonzalez G, Memon MA, Braidy N, Guillemin GJ. Neuroprotective effect of natural products against Alzheimer's disease. Neurochem Res. 2012;37(9):1829-42.

6. Zargar BA, Masoodi MH, Khan BA, Akbar S. Paeonia emodi Royle: Ethnomedicinal uses, phytochemistry and pharmacology. Phytochem Lett. Phytochemical Society of Europe. 2013;6(2):261-6.

7. Khan T, Mansoor Ahmad HK, MAK. Biological activities of aerial parts of Paeonia emodi. African $\mathrm{J}$ Biotechnol. 2005;4(November):1313-6.

8. Singh BP, Deepa. Critical analysis of kampavata (parkinsonism). Int Ayurvedic J. 2015;3(6):1767-73. 
9. Zargar BA, Masoodi MH, Ahmed B, Ganie SA. Antihyperlipidemic and Antioxidant Potential of Paeonia emodi Royle against High-Fat Diet Induced Oxidative Stress. ISRN Pharmacol. 2014;2014:182362.

10. Blesa J, Phani S, Jackson-Lewis V, Przedborski S. Classic and new animal models of Parkinson's disease. J Biomed Biotechnol. 2012;2012.

11. Kirby ED, Jensen K, Goosens KA, Kaufer D. Stereotaxic surgery for excitotoxic lesion of specific brain areas in the adult rat. $J$ Vis Exp. 2012;(65):e4079.

12. Agrawal SS, Gullaiya S, Dubey V, Singh V, Kumar A, Nagar A, et al. Neurodegenerative shielding by curcumin and its derivatives on brain lesions induced by 6-OHDA model of Parkinson's disease in albino wistar rats. Cardiovasc Psychiatry Neurol. 2012;2012:8.

13. Shalavadi MH, Chandrashekhar VM, Avinash SP, Sowmya C, Ramkishan A. Neuroprotective activity of Stereospermum suaveolens DC against 6-OHDA induced Parkinson's disease model. Indian J Pharmacol. 2012;44(6):737-43.

14. Campbell JC, Jeyamohan SB, Cruz PD La, Chen N, Shin D, Pilitsis JG. Place conditioning to apomorphine in rat models of Parkinson's disease: Differences by dose and side-effect expression. Behav Brain Res. Elsevier B.V. 2014;275:114-9.

15. Konieczny J, Czarnecka A, Lenda T, Kamińska K, Antkiewicz-Michaluk L. The significance of rotational behavior and sensitivity of striatal dopamine receptors in hemiparkinsonian rats. A comparative study of lactacystin and 6-OHDA. Neuroscience. 2017;340:308-18.

16. Chen XY, Li J, Qi WQ, Shen SH. Experimental change on dopaminergic neurons in striatum of Parkinson disease rats. 2007;1085-90.

17. Ellis JM, Fell MJ. Current approaches to the treatment of Parkinson's Disease. Bioorg Med Chem Lett. 2017;27:4247-55.

18. Pathak- Gandhi N, Vaidya ADB. Management of Parkinson's disease in Ayurveda: Medicinal plants and adjuvant measures. $\mathrm{J}$ Ethnopharmacol. 2017;197:46-51.

19. Uddin G, Sadat A, Siddiqui BS. Phytochemical Screening. In vitro Antioxidant and Antimicrobial Activities of the Crude Fractions of Paeonia emodi Wall. Ex Royle. 2013;17(3):367-73.

20. Abbas Zaidi SM, Pathan SA, Singh S, Ahmad FJ, Jamil SS, Khar RK. Effect of Repeated Administration of Paeonia emodi Wall Root Extract in Experimental Models of Epilepsy and Behavior. J Pharmacol Toxicol. 2012;7:64-77.

21. Sharma PV. Dravyaguna-Vidnyana. $2^{\text {nd }}$ ed. Chaukhana Bharati Academy; 2001:86.

22. Duty S, Jenner P. Animal models of Parkinson's disease: A source of novel treatments and clues to the cause of the disease. $\mathrm{Br} \mathrm{J}$ Pharmacol. 2011;164(4):1357-91.

23. Zhang K, Jiayu G, Zaijun Z. Evaluation of Parkinson's disease in 3 rat models induced by three different unilateral injections of. J Pharm Biomed Sci. 2015;5(11):842-7.

24. Simola N, Morelli M, Carta AR. The 6hydroxydopamine model of Parkinson's disease. Neurotox Res. 2007;11(3-4):151-67.

25. Carvalho MM, Campos FL, Coimbra B, Pêgo JM, Rodrigues $\mathrm{C}$, Lima $\mathrm{R}$, et al. Behavioral characterization of the 6-hydroxidopamine model of Parkinson's disease and pharmacological rescuing of non-motor deficits. Mol Neurodegener. 2013;8(1):14.

26. Blandini F, Armentero MT. Animal models of Parkinson's disease. FEBS J. 2012;279(7):1156-66.

27. Singh S, Ahmed R, Sagar RK, Krishana B. Neuroprotection of the nigrostriatal dopaminergic neurons by melatonin in hemiparkinsonium rat. Indian J Med Res. 2006;124(OCT.):419-26.

28. Antala BV, Patel MS, Bhuva SV, Gupta S. Protective effect of methanolic extract of Garcinia indica fruits in 6-OHDA rat model of Parkinson's disease. 2012;44(6):683-7.

29. Olsson M, Nikkhah G. Forelimb Akinesia in the Rat Parkinson Model. Differential Effects of Dopamine Agonists and Nigral Transplants as Assessed by a New Stepping Test. J Neurosci. 1995;15(5):3863-75.

30. AKS, Vijayalakshmi K, Nagappan P, Balima S. Effect of sesamol in association with folic acid on 6-ohda induced parkinsonian animals-biochemical, neurochemical and histopathological evidence. Asian J Pharm Clin Res. 2017;10(4):6-10.

Cite this article as: Jalgaonkar SV, Kamble AP, Parmar UI, Kurle DG, Bedrekar MS, Gursahani M. Evaluation of the protective effect of Paeonia emodi Wall on rat model of Parkinson's disease induced by 6 hydroxy dopamine. Int J Basic Clin Pharmacol 2018;7:2137-43. 